\title{
Preparation of amine coated silver nanoparticles using triethylenetetramine
}

\author{
L RAMAJO*, R PARRA, M REBOREDO and M CASTRO \\ Institute of Research in Materials Science and Technology (INTEMA), \\ (CONICET - University of Mar del Plata), Juan B Justo 4302 (B7608FDQ), Mar del Plata, Argentina \\ e-mail: 1ramajo@fi.mdp.edu.ar
}

MS received 17 August 2007; revised 23 June 2008

\begin{abstract}
This article presents a simple method towards the preparation of functionalized silver nanoparticles in a continuous medium. Silver nanoparticles were obtained through $\mathrm{AgNO}_{3}$ chemical reduction in ethanol and triethylenetetramine was used to stabilize and functionalize the metal. The product was characterized with X-ray diffraction (XRD), Fourier-transformed infrared spectroscopy (FTIR), UVvisible spectroscopy, thermal gravimetric analysis (TGA) and transmission electron microscopy (TEM). Monocrystalline silver particles with cubic structure and an average size of $20 \mathrm{~nm}$ were obtained. The results reveal that it is possible to synthesize Ag nanoparticles functionalized with amine groups and that particle size is influenced by the processing route.
\end{abstract}

Keywords. Chemical reduction; electron microscopy (STEM, TEM and SEM); optical properties.

\section{Introduction}

Metal nanoparticles are being intensively investigated because of their unique optical, electric, and catalytic properties which make them a potential material for utilization in the field of medicine, optoelectronics, composites and in many other frontier areas of science and technology. ${ }^{1-3}$

Much work has been done to improve the electrical and mechanical properties of epoxy-based electrically conductive adhesives in the past decade. ${ }^{4}$ Some results also showed that a good interface between silver particles and the epoxy resin can promote the conductivity, which play an important role for the performance of dielectric composites. In this way, amine coated $\mathrm{Ag}$ nanocomposite can be used by increasing the $\mathrm{Ag} /$ epoxy composite conductivity employing a low $\mathrm{Ag}$ amount.

In general, silver and gold nanoparticles can be synthesized by several methods, for example: chemical reduction in aqueous solutions, ${ }^{5-7}$ chemical and photo reduction ${ }^{8,9}$ and ultrasonic irradiation..$^{10,11}$ However, most of these procedures only render stable silver dispersions at a relatively low concentration of the metal; hence, they are not suitable for

\footnotetext{
*For correspondence
}

large-scale manufacturing. ${ }^{12}$ To prepare a stable colloidal solution of metal nanoparticles it is necessary to cap the metal with an appropriate chemical agent like a polymer or a surfactant with specific functional groups that can interact with the metal surface. ${ }^{13}$

In the surfactant-assisted synthesis, various physicochemical properties, including the relative concentration of the surfactant, its molecular weight and the $\mathrm{pH}$ of the solution, among others, have a great influence on the morphology of the particles as well as on the final optical, electrical, catalytic and/or magnetic properties. ${ }^{14,15}$

The objective of this work is to study the synthesis of $\mathrm{Ag}$ nanoparticles with amine functional groups for applications in electronics. The nanoparticles were obtained by chemical reduction of $\mathrm{AgNO}_{3}$ in ethanol, using triethylenetetramine as surfactant, according to a simple method developed by Frattini and coworkers. ${ }^{16}$ They prepared a diluted Ag nanoparticle solution by chemical reduction in alcoholic medium using aminosilanes as surfactants in different concentrations without the precipitation of particles. In this work, an analysis of the temperature influence on the precipitation of silver nanoparticles was carried out. Also, the nanoparticles were functionalized using triethylenetetramine in order to improve the adhesion between the epoxy resin and the filler. 


\section{Experimental}

The chemicals used during this research were of high purity. The triethylenetetramine (DEH 24) was supplied by Dow Chemical, whereas the ethanol (99.5\%) and silver nitrate $\left(\mathrm{AgNO}_{3} ; 99.5 \%\right)$ were obtained from Cicarelli and Fluka, respectively.

$300 \mathrm{mg}$ of $\mathrm{AgNO}_{3}$ were added to $200 \mathrm{ml}$ of ethanol in a glass container at two different temperatures, 50 and $70^{\circ} \mathrm{C}$, under constant stirring. The triethilenetetramine, previously dissolved in ethanol, was dispersed into the $\mathrm{AgNO}_{3}$ alcoholic solution in order to obtain a $1: 10 \mathrm{AgNO}_{3}$ : Amine ratio. The UVVis absorption spectra of these samples were afterwards acquired with a Shimatzu PC160A Plus UVvis spectrophotometer using ethanol as reference.

The systems were precipitated by alcohol evaporation at $90^{\circ} \mathrm{C}$ for $2 \mathrm{~h}$. The solution prepared at $50^{\circ} \mathrm{C}$ and treated at $90^{\circ} \mathrm{C}$ was labelled $\mathrm{Ml}$ whereas the system prepared at $70^{\circ} \mathrm{C}$ and treated at $90^{\circ} \mathrm{C}$ was labelled M2. The latter showed the precipitation of particles before the evaporation of the alcohol. As a result, a solution of amine with precipitated silver nanoparticles was achieved.

These samples were characterized by X-ray diffraction with a Philips PW1030 equipment running with $\mathrm{CoK} \alpha$ radiation and an $\mathrm{Fe}$ filter at $40 \mathrm{kV}$ and $30 \mathrm{~mA}$. The crystallite size, L, was estimated with the Scherrer's equation $(\mathrm{L}=\mathrm{K} \gamma /(\beta \cos \theta)) ;{ }^{17}$ where $\gamma$ is the wavelength of the source $(0 \cdot 179 \mathrm{~nm}), \beta$ is the full width at half-maximum intensity (fwhm) of the diffraction line, $\theta$ is the Bragg angle for the corresponding peak and $\mathrm{K}$ is a constant equal to $0.9 .{ }^{10}$

Transmission electron microscopy (TEM) was performed with a Philips CM200 with an acceleration voltage of $200 \mathrm{kV}$. The detection of amine groups in the product after the synthesis was achieved by FTIR using a Mattson Genesis II spectrometer.

Finally, amine-coated particles were analysed by thermogravimetric analysis (TGA, Shimadzu TGA50) under a flow of synthetic air at a heating rate of $10^{\circ} \mathrm{C} / \mathrm{min}$ from room temperature to $700^{\circ} \mathrm{C}$.

\section{Results and discussion}

Figure 1 shows the UV-Vis absorption spectra of M1 and M2 obtained before the alcohol evaporation. The samples exhibited the usual yellow colour and the characteristic absorption band between 350$450 \mathrm{~nm}$. It can be assumed that the small intensity of the band in M1 is attenuated in M2 because of pre- cipitation. This plasmon band is produced by the conduction electrons of silver which move collectively around the particle, perturbing the electron density, and generating the oscillation of the charges. It usually appears at $415 \mathrm{~nm}$; however, in our samples, the band shift could be attributed to the agglomeration of particles and to their non-spherical shape. $^{18}$

The XRD patterns registered for $\mathrm{M} 1$ and $\mathrm{M} 2$ are shown in figure 2 . Both samples showed similar patterns with the characteristic peaks of the cubic structure of Ag [JCPDS 04-0783]. Due to the small particle size, the diffracted planes were translated into quite

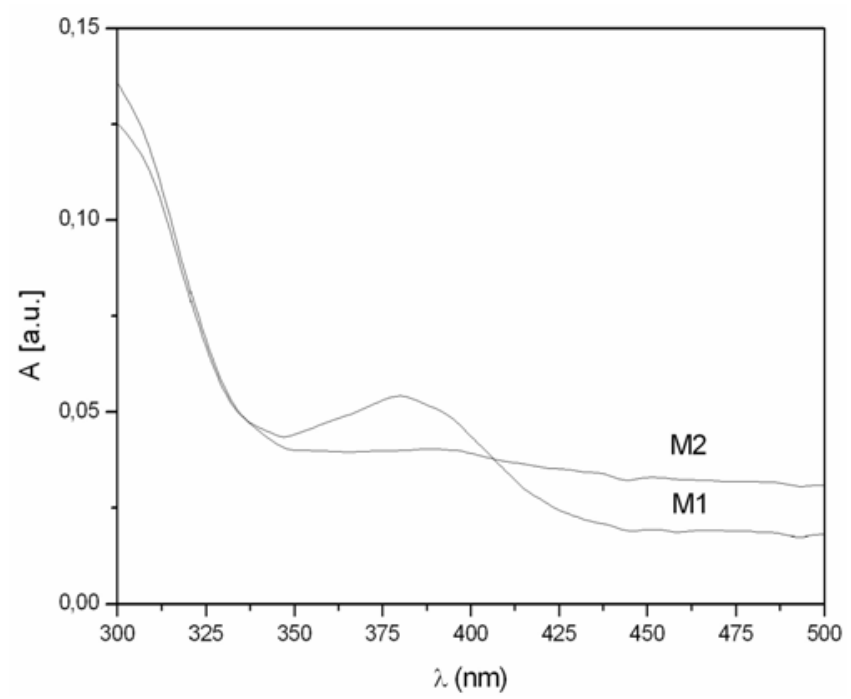

Figure 1. UV-Vis absorption spectra of dissolution M1 and M2 obtained before alcohol evaporation.

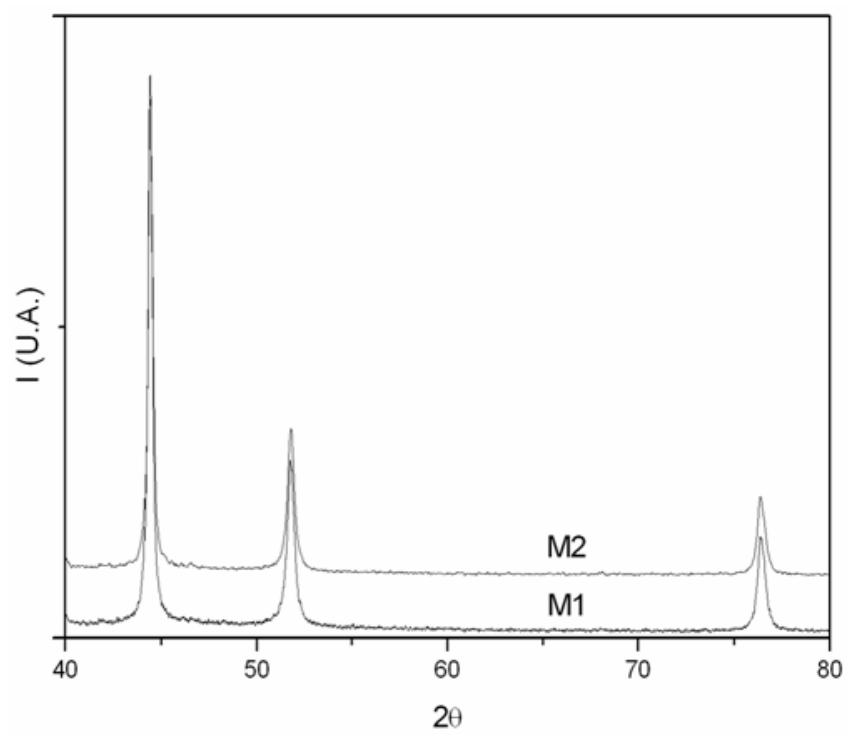

Figure 2. XRD patterns of samples M1 and M2. 


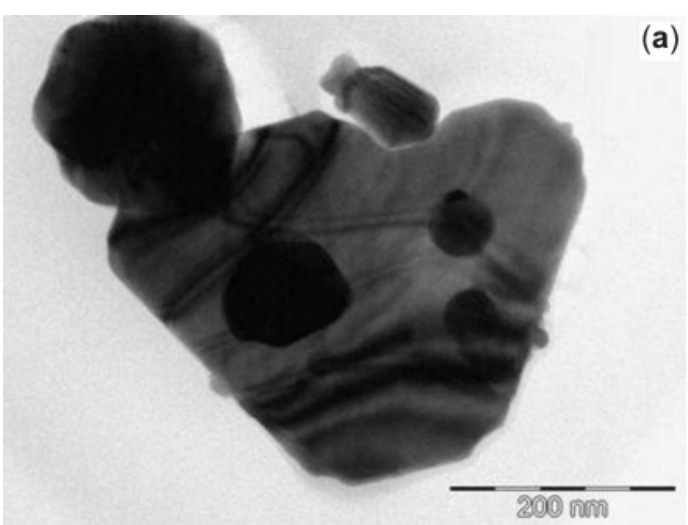

(b)

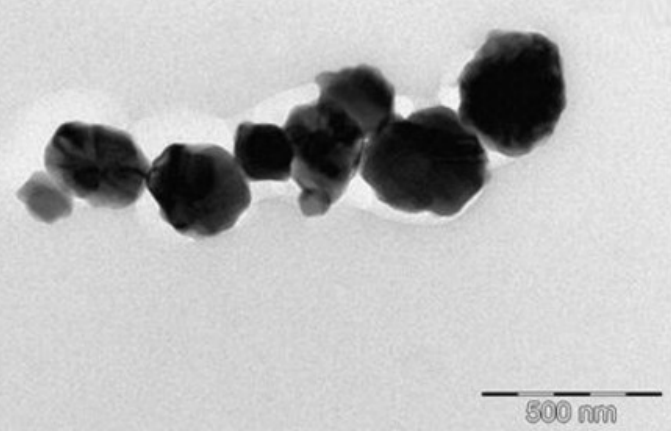

(a)

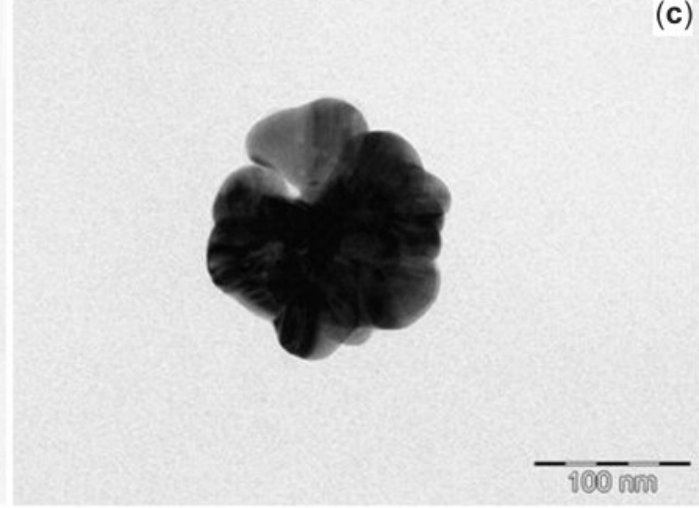

(d)

Figure 3. TEM pattern of the silver nanoparticles obtained through different processing routes. (A, B: M1; C, D: M2).

broad signals. For this reason, the equation of Scherrer was used in order to gain more information of the particle size. The silver average particle size calculated was approximately $20 \mathrm{~nm}$.

The TEM images of samples M1 and M2 are shown in figures $3(a, b)$ and $(c, d)$, respectively. Aggregates of particles with irregular size can be differentiated. Furthermore, the particles are not spherical and the average particle size calculated with the Scherrer's equation does not match with the TEM results because of the agglomeration. M1 displayed a higher average particle size and a higher degree of agglomeration than M2. Sizes range from 50 to $400 \mathrm{~nm}$ for M1 sample, and from 25 to $200 \mathrm{~nm}$ for M2 are observed.

The agglomeration effect can be ascribed to the adsorption of a molecule of triethylenetetramine at different $\mathrm{Ag}$ nanoparticles simultaneously. In general, it is believed that samples prepared at higher temperatures (M2) have a better morphology. At low temperature, the silver reduction is slower and the amine nuclei may form and grow in solution. On the other hand, at higher temperature, silver reduction proceeds faster and the formation of the complex Ag-amine is possible. ${ }^{19}$
TEM analyses were complemented with EDS and with the acquisition of SAED patterns (figure 4) for phase identification and chemical characterization of the sample M2. The SAED pattern (figure 4a) was indexed as cubic phase monocrystalline silver (JCPDS 04-0783), with a unit cell of $4.086 \AA$. The EDS spectrum showed the presence of $\mathrm{Ag}$ and $\mathrm{Cu}$ from the copper grid.

The FTIR spectra (3750-750 $\mathrm{cm}^{-1}$ ) of triethylenetetramine and samples $\mathrm{M} 1$ and $\mathrm{M} 2$ are shown in figure 5 . The bands at 2850 and $2950 \mathrm{~cm}^{-1}$ observed in every sample are characteristic of the vibration modes $v_{\mathrm{a}}$ and $\nu_{\mathrm{b}}$ of the methylene groups $\left(-\mathrm{CH}_{2}-\right)$. Also, the bands at 1120 and $1480 \mathrm{~cm}^{-1}$ are typical of the $v$ $\mathrm{C}-\mathrm{OC}, \delta_{\mathrm{s}}-\mathrm{CH}_{2}$ and $\delta_{\mathrm{a}}-\mathrm{CH}_{3}$ vibrations, respectively. ${ }^{20}$ These vibration modes are invariant with respect to the formation of the complex and to the adsorption at the nanoparticles surface. Then, it is suggested that the alkyl chains adopt the stretched conformation irrespectively of the complex formation.

The spectra also show peaks at 1321, 1580 and $3400 \mathrm{~cm}^{-1}$ attributed to $v-\mathrm{C}-\mathrm{N}, \delta-\mathrm{NH}_{2}$ and $v_{\mathrm{a}}-\mathrm{NH}$, respectively. ${ }^{21}$ The position and relative intensity of these bands change with respect to the pure amine. The variation of the $-\mathrm{NH}_{2}$ and $-\mathrm{NH}$ infrared bands 
suggests the formation of links between the nanoparticles. ${ }^{21}$

In figure 6, a scheme with a single molecule linking two $\mathrm{Ag}$ nanoparticles is presented. ${ }^{22}$ In this model, the amine is linked to the Ag particles through the amine groups and no direct contact is established between the silver nanoparticles. Some researchers have attributed a key role to the amine in the $\mathrm{Ag}^{+}$reduction due to its decrease in the potential of $\mathrm{Ag}^{+} / \mathrm{Ag}\left(\mathrm{E}_{\mathrm{Ag}+/ \mathrm{Ag}}\right)$ promoting the reaction. ${ }^{16}$ However, there is still no substantial evidence that confirms this assumption.

The variation of the sample weight, and of its derivative $(\Delta W / \Delta T)$, with temperature for $\mathrm{M} 1$ and $\mathrm{M} 2$ can be observed in figures $7 a$ and $b$, respectively. According to both TGA curves, the thermal decomposition process is represented by multiple falls in
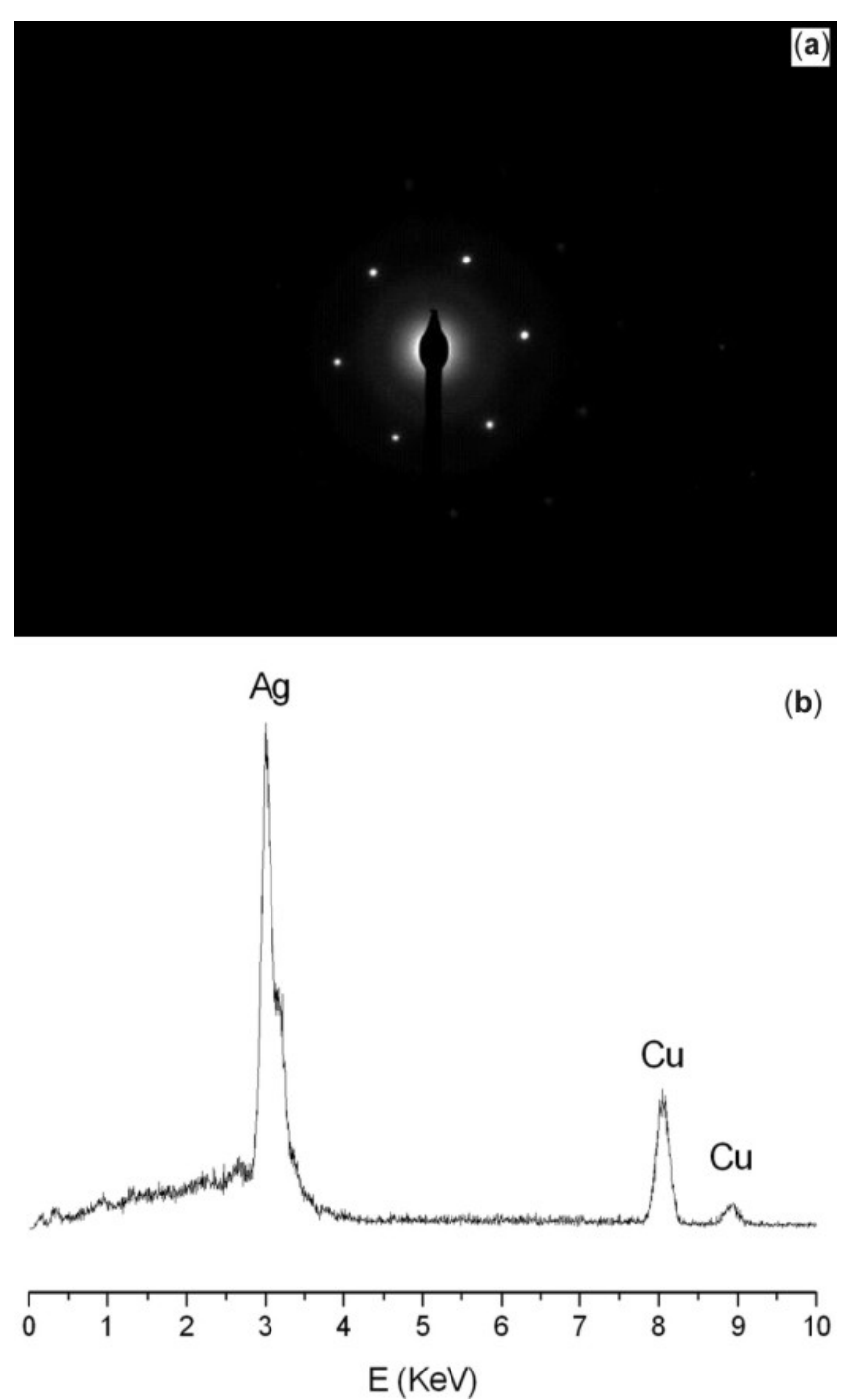

Figure 4. (a) SAD pattern and (b) EDS of the silver nanoparticles presented in the figure $3 \mathrm{~b}$. weight over the temperature ranges from 50 to 125 , 125 to 230,230 to 310 and 400 to $550^{\circ} \mathrm{C}$. Each of these changes was seen as a peak in the derivative curves. The weight loss between 50 and $125^{\circ} \mathrm{C}$ was attributed to residual alcohol evaporation, whereas the rest are due to the decomposition of triethylenetetramine. The residual mass $\left(\right.$ at $700^{\circ} \mathrm{C}$ ), in both samples was similar, 37 and $38 \%$, indicating the

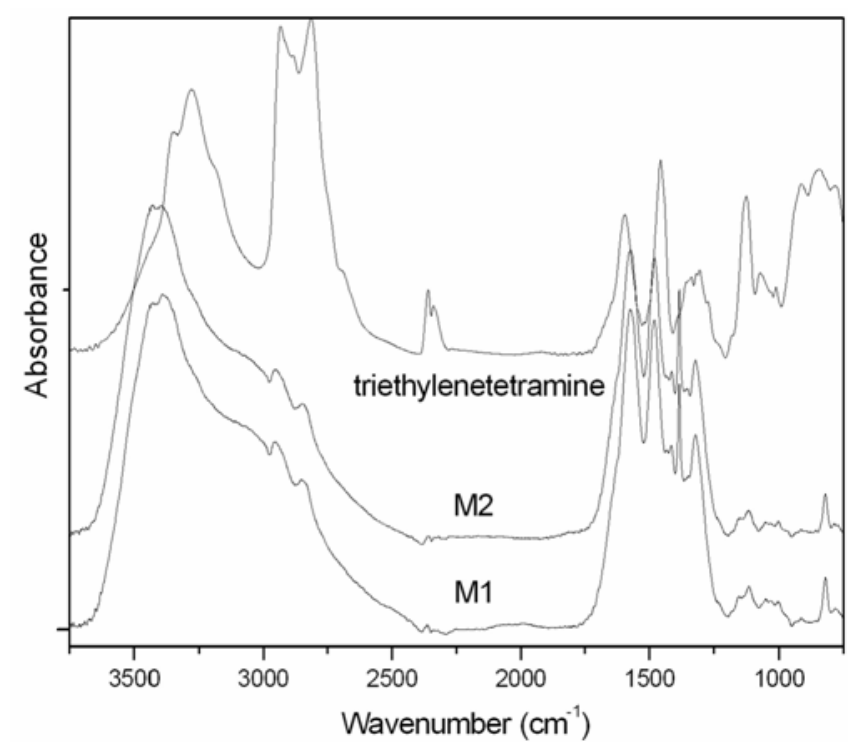

Figure 5. FTIR spectra of triethylenetetramine and Ag nanoparticles in M1 and M2.

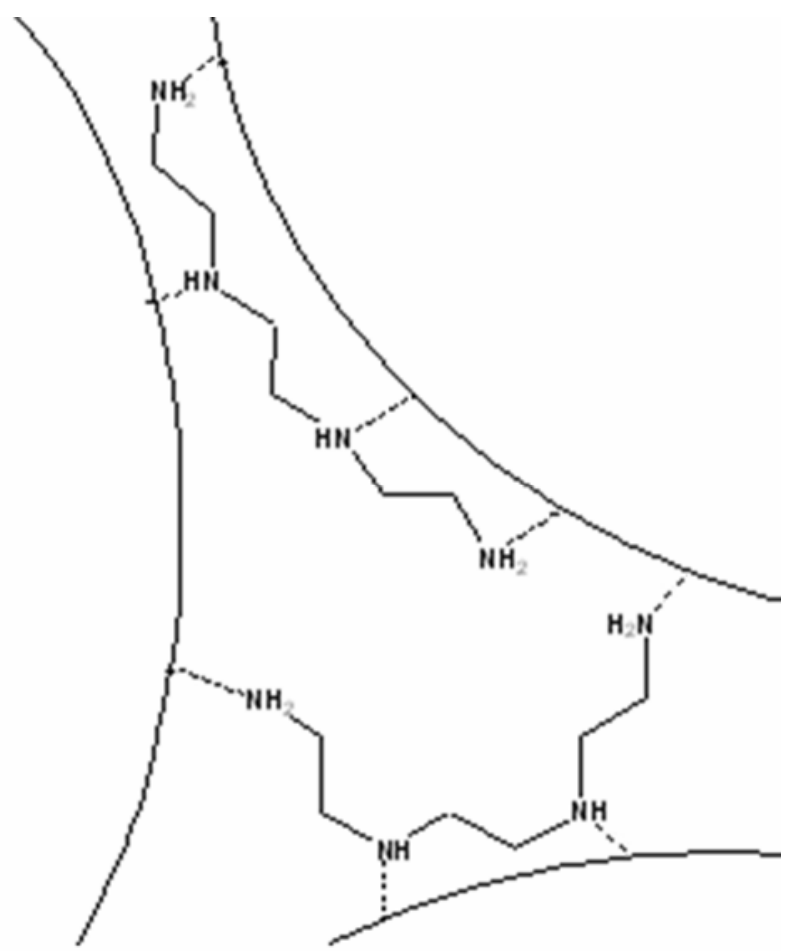

Figure 6. Schematic diagram of the mechanism of amine-induced nucleation of silver nanoparticles. 

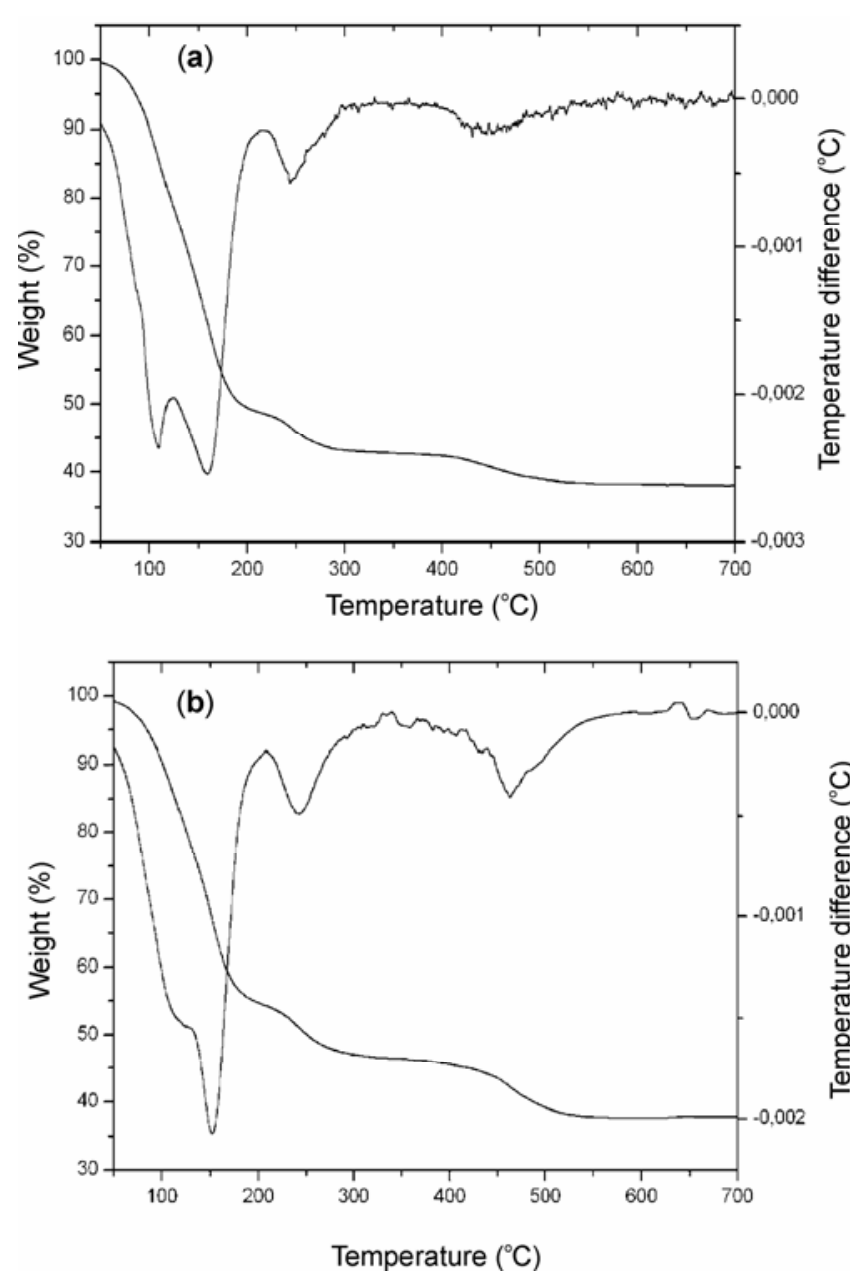

Figure 7. TG curves of Ag nanopartices synthesized by (a) $\mathrm{M} 1$ and (b) $\mathrm{M} 2$ routes.

high amount of organics in M1 and M2. On the other hand, it can be recognized that M2 did not show a well-defined peak at $100^{\circ} \mathrm{C}$, as $\mathrm{Ml}$ did. It can be due to a higher amount of alcohol in M1. In this way, the residual mass at $100^{\circ} \mathrm{C}$ in $\mathrm{M} 1$ was $90.5 \%$, while M2 presented $90.25 \%$.

\section{Conclusions}

Silver nanoparticles functionalized with an amine group were obtained via chemical reduction of $\mathrm{AgNO}_{3}$ in an alcoholic solution at two different temperatures, 50 and $70^{\circ} \mathrm{C}$.

Before alcohol evaporation, the systems prepared at the highest temperature presented a poor precipitation and did not show a plasmon band. After the alcohol was evaporated, both systems showed similar XRD patterns, FTIR spectra and TGA curves. Different morphologies were observed with TEM as samples prepared at $70^{\circ} \mathrm{C}$ showed a smaller average particle size.
Non-spherical nanoparticles were obtained and the presence of agglomerates was detected in both systems, although M2 sample presented less agglomeration. Triethylenetetramine was confirmed to act as a surface modifier and linking agent.

\section{Acknowledgements}

This work was supported by National Council of Science and Technology of Argentina (CONICET) and ANPCyT/FONCyT PICT 14738 (BID 1201/OCAR). Authors thank to Virginia Roldan of the National University of Rosario (UNR) for technical advice. Thanks are due to Dr Y Maniette for TEM analysis.

\section{References}

1. Spatz J P, Mössmer S and Hartmann C 2000 Langmuir 16407

2. Trindade T, Óbrien P and Pickett N L 2001 Chem. Mater 133843

3. Zhu L, Zheng X and Liu X 2004 J. Colloid Interf. Sci. 273155

4. Wong C P and Lu D 2000 3rd Electronics Packaging Technology Conference 214

5. Marzan L M and Tourino I L 1996 Langmuir 12 3585

6. Duff D G and Baiker G 1993 Langmuir 92301

7. Esumi K, Tano T, Torigoe K and Meguro K 1990 Chem. Mater. 2564

8. Petit C, Lixon P and Pelini M P $2001 \mathrm{~J}$. Phys. Chem. 9712974

9. Ohde H, Hunt F and Wai C M 2001 Chem. Mater. 13 4130

10. Lei Z and Fan Y 2006 Mater. Lett. 602256

11. Chen W, Zhang J Y and Di Y 2003 Appl. Surf. Sci. 221280

12. Sondi I, Goua D V and Matijevic E 2003 J. Colloid Interf. Sci. 26075

13. Mitra A and Bhaumik A 2007 Mater. Lett. 61659

14. Nabika H, Akamatsu K, Mizuhata A M and Kajinami S 2002 J. Mater. Chem. 122408

15. Mitra N and Imae T 2004 Chem. Lett. 33930

16. Frattini A, Pellegri N, Nicastro D and De Sanctis O 2005 Mater. Chem. Phys. 94148

17. Fukushima T, Kosaka A and Ishimura Y 2003 Science 3002072

18. He R, Qian X, Yin J and Zhu Z 2002 J. Mater. Chem. 123783

19. Pastoriza-Santos I and Marzán L M 2000 Pure Appl. Chemical 7283

20. Romão B M V, Pardini C, Dutra R C L and Burel F 2003 Polímeros: Ciência e Tecnologia 13173

21. Manna A. Imae T, Iida M and Hisamatsu N 2001 Langmuir 176000

22. Sun X and Luo Y 2005 Mater. Lett. 593847 